\title{
Foreword: South African Journal of Geomatics special edition
}

This special edition of the South African Journal of Geomatics is the culmination of efforts by scholars and practitioners in South Africa to highlight the development and growth of geospatial research in the country. The outcome of this work is a unique collection of 14 articles that demonstrate the range, innovation and uniqueness in geomatics research across this region of the world. I am sure you will find this special edition an interesting read.

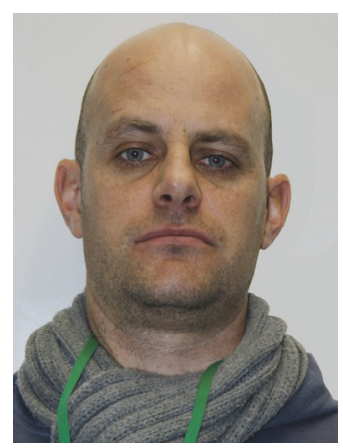

Prof. Gregory Breetzke

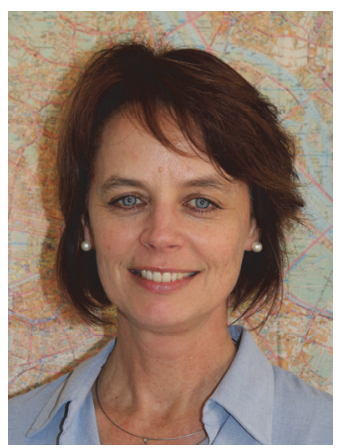

Prof. Serena Coetzee

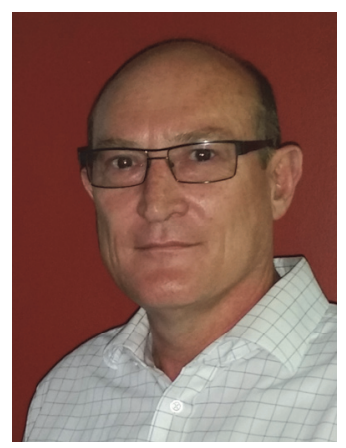

Prof. Fred Cawood

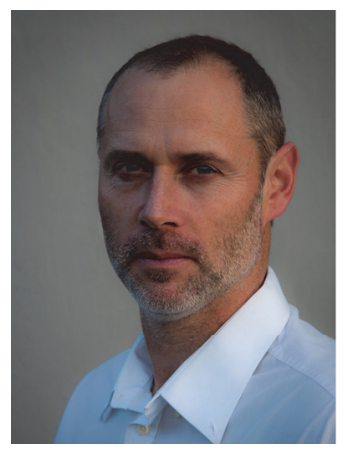

Prof. Julian Smit

From a practical perspective, Koech Cheruiyot and colleagues apply a spatial statistical approach to the 2013 Quality of Life (QoL) survey to analyse spatial patterns of dissatisfaction with the performance of local government in Gauteng. Their work highlights the need for incorporating spatial analysis in the formulation of policy aimed at improving government performance. In a similar vein, Sanet Eksteen and colleagues develop a methodology to measure service delivery in Gauteng. They propose to use their Fortunate Index to determine if government organisations provide for the needs of their communities. Bosiu Lefulebe highlights the importance of using indigenous knowledge in GIS analysis by using a case study approach aimed at developing strategies to lower incidences of crime in Khayelitsha, Cape Town. Richard Wonnacott and colleagues show how Global Navigation Satellite Systems (GNSS), Interferometric Synthetic Aperture Radar (InSAR) and In-Situ Micro Gravity Measurements can be used as tools to better manage and monitor scarce water supplies in the country. Using the South African Road Classification and Access Management Manual (TRH26) as a guideline, Pryaska Veramoothea functionally classifies the Gauteng provincial road network and shows how an accurate spatial representation of the current Gauteng provincial road network can be developed using an appropriate GIS. Zakariyyaa Oumar assesses the potential of Landsat 8 to rapidly map fire scars in KwaZulu-Natal. This work can aid disaster management response teams in emergency efforts in the province. Keagen Liebenberg and colleagues investigate the cause and impact of acid mine water-induced seismicity in Johannesburg and find a strong indication that the presence of underground mining areas positively influences the occurrence of seismic events in the city.

From a technical perspective, Nurudien Dawood and Siddique Motala evaluate an animated and static time series map of District Six, Cape Town, and develop a framework to enhance the map reader's experience in visualising time series spatial data. Kevin Musungu and Dorette Jacobs present a case study methodology for the development and testing of a web GIS that can be optimised for smartphones and tablets so that communities can access updated information while using the Theewaterskloof Dam for fishing or other recreational activities. Using a case study approach in the Greater Limpopo Trans-frontier Conservation Area (GLTFCA), Erika Pretorius proposes techniques for improving the potential of pixel-based supervised classification in the absence of quality ground truth data. Hamid Ashraf and Frederick Cawood outline a geospatial subsidence modelling method for the Sterkfontein Caves in South Africa. This model is used to assess the risk to public safety of land with shallow caves underneath. 
From an educational perspective, Paddington Hodza and colleagues compare international academic programmes in geomatics, geoinformatics and geographic information science and technology (GIS\&T) at three universities located in Europe, Africa and America. They found that there is not a one-size-fits-all strategy for establishing, shaping and sustaining geo(infor)matics / GIS\&T programmes across varying contexts and highlight differences in the origins, development and composition of the respective programmes.

Finally, Samy Katumba and Serena Coetzee illustrate the use of the constructed taxonomy in semantic annotation of web resources such as HTML pages with spatial metadata on the Web, while Julian Smit and Serena Coetzee clarify the requirements for setting up a national observatory in support of evidence-based planning in South Africa.

The articles in this special edition reflect a cross-section of new and contemporary work in geomatics research in southern Africa. They also provide an opportunity for the geospatial community in South Africa to share and learn from an exchange of ideas and research work. We hope that this special edition, in collaboration with the Geomatics Indaba 2015, will spawn new geospatial initiatives, foster current linkages and solidify existing collaborations in research and in the professional development of our discipline.

\section{Guest section editor}

Prof. Gregory Breetzke (University of South Africa)

Members of the Geomatics Indaba 2015 academic programme committee

Prof. Fred Cawood (University of the Witwatersrand)

Prof. Julian Smit (University of Cape Town)

Prof. Serena Coetzee (University of Pretoria) 